Aletria, Belo Horizonte, v. 28, n. 3, p. 183-199, 2018

\title{
Políticas da morte na ficção de José do Patrocínio
}

\section{Politics of Death in the Fiction of José do Patrocínio}

\author{
Marcelo dos Santos \\ Universidade Federal do Estado do Rio de Janeiro, Rio de Janeiro, Rio de Janeiro / Brasil \\ m.santos1977@gmail.com
}

Resumo: Em 1877, o escritor e jornalista José do Patrocínio publicou Motta Coqueiro ou A pena de morte, ficção-libelo contra a pena de morte. Ficcionalizando os fatos em torno da história d'“A fera de Macabu", Patrocínio produziu uma narrativa considerada protonaturalista, pela expressão, e ideologicamente comprometida com as teorias raciais da época. Contudo, propõe-se aqui uma leitura alternativa, que deve deixar assinalado que, apesar do uso de modos e formas de expressão e pensamento do final do século XIX brasileiro, o livro de Patrocínio parece realizar um mapa dos afetos na sociedade oitocentista brasileira. Sendo assim, Motta Coqueiro exemplificaria caminhos de uma ficção afro-brasileira que expressa, além das contradições de uma sociedade estruturalmente escravocrata, a produção do ódio que condena a todos.

Palavras-chave: José do Patrocínio; negritude; escravidão; pena de morte, crime de ódio.

Abstract: In 1877, writer and journalist José do Patrocínio published Motta Coqueiro or The Death Penalty, a fictional protest against the death penalty. By fictionalizing the facts around the story of "The Beast of Macabu", Patrocínio produced a narrative considered proto-naturalist, and ideologically committed to the racial theories of the time. However, this article proposes an alternative reading, which argues that, despite being a product of late nineteenth-century Brazilian thinking, Patrocínio's book is critical of entrenched attitudes about racial difference.

Keywords: José do Patrocínio; blackness; slavery; death penalty; hate crime. 


\section{Ferguson, Alcolu, Macaé}

Em 2014, a cidade de Ferguson, no estado do Missouri, nos EUA, foi alvo de uma série de protestos - veiculados na imprensa norte-americana como saques e manifestações de desordem civil - após a revelação do assassino do jovem afro-americano Michael Brown, de 18 anos. Com a notícia de que o acusado pela morte do jovem era o policial branco Darren Wilson, que teria assassinado Brown depois de uma abordagem em que este era supostamente suspeito de roubo, as manifestações se acirraram, e o governo decretou estado de exceção no local. O episódio, acontecido durante o governo de Barack Obama, mobilizou a sociedade norte-americana e reacendeu as discussões sobre racismo no país, pois a reação policial contra a população predominantemente afro-americana de Ferguson começou a ser considerada um caso de racismo institucionalizado.

Na cidade de Alcolu, no estado da Carolina do Sul, também nos EUA, George Junius Stinney Jr., de 14 anos, enfrentou um júri de homens brancos por causa da acusação de estupro e assassinato de duas meninas. Stinney foi condenado à morte na cadeira elétrica, e sua execução se deu em Colúmbia no ano de 1944. No mesmo ano dos tumultos de Ferguson, a justiça reconsiderou o caso de Alcolu, revendo o veredicto e declarando o réu inocente, 70 anos após a pena de morte ter sido aplicada a Stinney.

Condenado à forca em 1855, no município de Macaé, no Rio de Janeiro, Motta Coqueiro teve sua pena de morte decretada após reviravoltas no processo judicial, especialmente quando os depoimentos de alguns escravizados, entre eles a escravizada denominada Balbina, acusaram Motta Coqueiro. Manuel da Motta Coqueiro, branco e com posses, foi acusado de assassinar uma família que habitava suas terras. A filha de Francisco Benedito da Silva, meeiro das terras de Motta Coqueiro, se envolvera com o fazendeiro, e, por conta desse envolvimento, Motta Coqueiro e o meeiro começaram uma série de rixas e perseguições até o fatídico assassinato de toda a família de Benedito. Sendo senhor de escravizados, Motta Coqueiro não poderia ser confrontado com depoimentos de seus escravizados, segundo o Código Criminal vigente na época. Contudo, os depoimentos, somados à negação da graça imperial e ao inflamado clima pós-Lei Eusébio de Queirós, precipitaram a condenação de Motta Coqueiro. $\mathrm{O}$ fazendeiro alegou inocência até o último momento, embora as circunstâncias levassem a crer que ele seria 
provavelmente o mandante do crime. Porém, as muitas falhas do processo criminal foram motivo para posteriores especulações sobre a inocência de Motta Coqueiro ou, ao menos, de desconfianças acerca da condução do processo. Essas suspeitas levaram o escritor José do Patrocínio a escrever a ficção Motta Coqueiro ou A pena de morte, em 1877.

Distantes geográfica e temporalmente, os fatos narrados acima, dispostos em sequência, revelariam algum tipo de elo para além de seus desfechos trágicos? Os fatos de Ferguson e Alcolu parecem, à primeira vista, sintomas de um mesmo problema: o racismo latente das instituições de vigilância e punição. $\mathrm{O}$ caso Motta Coqueiro se mostra diferente dos anteriores, uma vez que a condenação do fazendeiro, branco, não revelaria a face racista, já que o condenado é identificado às figuras da opressão.

$\mathrm{O}$ fato ficcionalizado por José do Patrocínio, todavia, conforme este artigo visa evidenciar, revela uma forma complexa de lidar com o contexto do referido caso. Narrar os acontecimentos de Macaé, duas décadas depois, é encenar, a partir de outros aspectos, fatos que doravante deslizariam para o campo (por vezes minado) de possibilidades que o ficcional pode oferecer. Além disso, reescrever o caso, como o fez Patrocínio, é inscrever nele uma defesa ideológica, contra a pena de morte, uma vez que o fato é exemplar da sensibilização da opinião pública diante da nova realidade brasileira dos anos de 1870 .

É preciso atentar, também, para a possibilidade que o livro de Patrocínio traz em estado latente: diante dos quadros estéticos e enunciações disponíveis na segunda metade do século XIX, Motta Coqueiro ou A pena de morte não pode ser percebido integralmente se sua análise apenas o conforma numa ou noutra tendência estética da época. Conhecido como representante da voz da negritude em ambiente abolicionista, Patrocínio, neste folhetim, parece resvalar para uma enunciação conservadora, refém das dicções hegemônicas. Porém, o que se assinala desde agora, é que essa seria uma alternativa de leitura mais conformada a uma estabilização da ficção diante dos quadros estéticos vigentes. A adequação a esses mesmos quadros, no caso de Motta Coqueiro, não se faz sem um desvio, sem certas fraturas que demonstram um incômodo ou desadaptação a esses mesmos moldes. Nesse sentido, Motta Coqueiro, sem exemplificar necessariamente um libelo abolicionista, trama uma alternativa de expressão da negritude a partir da escolha do tema - contra a pena de morte - e da configuração de uma paisagem sensível não branca. 


\section{Percursos de uma tese}

Motta Coqueiro ou A pena de morte foi publicado em livro em 1877, depois de ter saído como folhetim na Gazeta de Notícias durante o mesmo ano. Por ser jornalista conhecido, a figura de José do Patrocínio abolicionista parece encobrir a sua avaliação como ficcionista, sempre legando-o ao genérico do molde da literatura pós-romântica - essa é a posição de boa parte da historiografia literária brasileira, com exceções marcantes, segundo apresenta Raimundo Magalhães Jr. (1969): Silvio Romero, Lúcia Miguel-Pereira (que, apesar de manter Patrocínio no campo dos escritores de segundo plano, dá destaque ao inusitado do primeiro romance) e Nilo Bruzzi, poeta e biógrafo de literatura, que tenta reconhecê-lo como escritor em sua biografia José do Patrocínio, romancista, editada em 1959.

É por isso fundamental a edição de Motta Coqueiro, preparada por Dirce Cortes Riedel em 1977, com apêndice contendo textos relacionados ao caso Motta Coqueiro, e iniciada com o ensaio de Silviano Santiago, intitulado "Desvios da ficção". No referido ensaio, o crítico desvenda com acuidade o modo como José do Patrocínio manipula a fórmula do romance de tese a fim de pôr a ficção a serviço de uma ideologia, o que comprometeria fortemente a autonomia do imaginário. Tal romance de tese é retoricamente construído a favor de uma única verdade: provar indutivamente a inocência de Motta Coqueiro no caso do assassinato da família de seu meeiro Francisco Benedito.

Apesar de apontar o molde do romance de tese, Silviano conduz a uma leitura paralela que pode realocar o romance oitocentista diante dos olhos contemporâneos para a observação da exata descrição dos locais e da sondagem psicológica do escravizado, esta última provavelmente ligada à memória afetiva de Patrocínio. Na esteira de Silviano, Marcos Teixeira de Souza (2015) analisa como a região de Macabu, no município de Macaé, principalmente no ambiente da senzala e nos espaços de circulação dos escravizados, aparece transfigurada pela memória que Patrocínio guardava do tempo em que viveu em Campos dos Goytacazes, interior do Rio de Janeiro.

O ensaio de Silviano tem o mérito de se distanciar das avaliações sobre o tema da crítica à pena de morte para salientar que "[...] Motta Coqueiro se afasta da rotina do romance brasileiro do século XIX, e de certa forma é pioneiro nessa tentativa de configurar socialmente o 
ambiente da senzala". ${ }^{1}$ Essa é uma importante reavaliação da obra, mas também da função do romance oitocentista a partir da obra de Patrocínio, quando se percebe a relação entre a memória afetiva e a ficção. Nessa junção inusitada para a avaliação crítica do livro, Silviano argumenta que o escrito de Patrocínio pode sobreviver especialmente por ser da autoria de Patrocínio, por momentos em que a memória do autor e ficção trabalham juntas, deixam-se levar “ "[...] pelo próprio texto, pela sua própria memória afetiva, como todo e qualquer bom romancista de ficção".

Assim, a memória afetiva do negro brasileiro está expressa nas filigranas do folhetim, constituindo, ao considerarmos as palavras do crítico, um importante arquivo de afetos e sensibilidades do "ser negro" no Brasil monárquico e escravista. A partir das reavaliações de Silviano Santiago e de Marcos Teixeira, dirijo o romance de Patrocínio para uma visada interpretativa da junção entre a defesa de uma tese - a inocência de Motta Coqueiro - ou de teses, como propõe Marcos Teixeira no texto referido - a submissão da mulher, o libelo contra a pena de morte, a exploração dos escravizados, etc. -, e essa memória afetiva ou construção de uma memória do "ser negro" a partir da expressão, cultura e modos de vida dos negros no ambiente em que Patrocínio fora criado. Esse complexo faz da malha textual de Motta Coqueiro uma máquina de sensações que capturam esteticamente as tensões sociais do Brasil escravocrata. Para isso, reconstituo adiante a trajetória de criação do romance, percorrendo o texto de Patrocínio a fim de recuperar uma certa complexidade da proposta narrativa e mostrar como a história de Motta Coqueiro, a possibilidade da injustiça fatal, funciona como episódio aglutinador de uma sociedade violenta.

Os fatos ligados a Motta Coqueiro, que agitaram os anos de 1850, tiveram sua reaparição nas páginas da Gazeta de Notícias por retransmissão do periódico Aurora Macaense. É impossível desvincular essa reaparição do interesse dos leitores de periódicos pelo bas fond, simbolizado pelo sucesso de livros como Os mistérios de Paris, de Eugène Sue (publicado no Jornal do Commercio em 1857), e pela proliferação dos registros de fait divers e das ocorrências criminais. O retorno do caso Motta Coqueiro é afinado a esse interesse e ao público da Gazeta, que tinha leitores adeptos de uma nova modernidade em que o escândalo e a

SILVIANO. Desvios da ficção, p. 18.

2 SILVIANO. Desvios da ficção, p. 21. 
violência vão se tornando pouco a pouco cotidianos. A ficção de José do Patrocínio representa uma possibilidade nada rara de especulação: mais do que um romance de tese, ela põe em movimento, dramaticamente, os argumentos que sustentariam a inocência de Motta Coqueiro, mesmo que a ideia seja rapidamente considerada absurda pela opinião pública.

Acompanhando-se a pré-publicação de Motta Coqueiro como folhetim na Gazeta, percebemos a feição opinativa do jornal, que francamente assume a posição contra a pena de morte. O efeito da falsa confissão no folhetim evidencia muito das práticas de leitura dos periódicos nos oitocentos. Nos anos de 1870, a Gazeta de Notícias representa a inovação na imprensa, abrindo o espaço para a publicação de debates antimonarquistas e abolicionistas e para a produção literária mais contestadora: é pelas suas páginas que passam Patrocínio, João do Rio, Machado de Assis e Euclides da Cunha. Motta Coqueiro é o primeiro folhetim em português da Gazeta, e é simbolicamente o tipo de folhetim produzido dentro das polêmicas do jornal. Veicular a defesa veemente da inocência do condenado não poderia se distinguir desse teor imaginativo, polêmico, de um suposto confessor aparecido no calor dos anos de 1870, anos de agitação política e social. O que podemos perceber, levando isso em consideração, é que o caso rediscutido motiva Patrocínio a vasculhar algo mais do que a condenação injusta, aquilo que justapõe condenação, injustiça, violência e negritude.

Além das notícias políticas, Patrocínio escreve na Gazeta a série "Ocorrências de rua", uma espécie de coluna de fait divers, informando sobre furtos, assassinatos e outras ocorrências policiais ao leitor carioca. $\mathrm{O}$ que chama atenção na coluna é a proliferação de tipos populares sofrendo as punições por seus delitos, e é notável como o colunista ressalta uma segunda condenação aos já condenados pela miséria, pela marginalidade. Essa tônica da coluna é importante para entender a construção das personagens de Motta Coqueiro: não somente a memória afetiva, mas o contato com essas personagens marginalizadas - alcóolatras, doentes mentais, escravizados detidos por praticar capoeira, mendigos, etc. -, deve ter forjado a exatidão descritiva das camadas marginalizadas dentro do romance. Recriando habilmente esse ambiente de uma urbanidade em crescimento, Patrocínio usava versos para legar ao leitor uma nova sensibilidade estética em meio ao contexto fugaz do jornal: 


\author{
Eram três da madrugada \\ Quando os bonecos de engonço \\ Zé Maria e João Afonso \\ Queriam rolo, talvez, \\ Com todos os transeuntes \\ Da Rua da Carioca. \\ Vem a guarda e os dois reboca \\ Para o meio do xadrez. ${ }^{3}$
}

Em suma, Patrocínio, nas “Ocorrências de rua”, reconstituía narrativamente a vida dos marginais na rua a partir das informações dos rondantes, policiais responsáveis pela manutenção da ordem pública. Por isso mesmo, talvez não surpreenda que a primeira cena de Motta Coqueiro, usando a técnica narrativa do flashback, se dê na rua, na praça pública em Macaé onde Motta Coqueiro sofreria a execução.

Aliadas a essa confecção de uma paisagem exterior de conflitos, em que marginais e populares se encontram, as contradições da sociedade escravocrata brasileira são debatidas por Patrocínio na Gazeta, quando este assina com o pseudônimo Proudhomme. Sobre a complexidade do escravismo, que Proudhomme tentava captar, Raimundo Magalhães Jr. comenta:

Consciência [do escravismo] que nem todos tinham, pois havia até negros e mulatos que eram donos de escravos e ferrenhos escravistas [...] É fácil imaginar a reação despertada pelo slogan de Proudhon [A escravidão é um roubo. Todo dono de escravo é um ladrão], de tendências nitidamente socialistas, convertido em arma contra a escravidão pelo nosso Proudhomme, que errava na grafia do nome, mas não nas intenções, que permaneciam fiéis ao pensamento original do célebre escritor francês... ${ }^{4}$

É pertinente a essa experimentação de formas e tons no jornal, a abertura de Motta Coqueiro. O primeiro capítulo é construído a partir da oposição entre uma voz dissonante, que ecoa a inocência proclamada por Motta Coqueiro, e a opinião pública:

\footnotetext{
3 MAGAlHÃES JR. A vida turbulenta de José do Patrocinio, p. 41.

4 MAGAlHÃES JR. A vida turbulenta de José do Patrocínio, p. 42.
} 
Homem tão honrado e bondoso, quanto gárrulo, o Sr. Martins naquela manhã discutiu com quase toda a população de Macaé, e o maior número das vezes concluiu repetindo a frase final da sua conversação com Luís de Sousa: É falso, é falso; o desgraçado morre inocente. ${ }^{5}$

Estilisticamente, a ficção de Patrocínio é formada pela sobreposição entre os discursos direto e indireto. Isso permite ao narrador sondar a possível psicologia das personagens e, via discurso direto, enfatizar dramaticamente as opiniões divergentes. Nesse confronto de discursos, desenha-se o problema do silenciamento: assumir uma voz sempre silenciada frente à manipulação da opinião pública é simbolicamente representar que a ficção realizada a partir da cena de execução denuncia, nessa sociedade, algo que faz calar violentamente as vozes dissonantes.

\section{O ódio que respiramos}

Em leitura panorâmica, a posição contrária à pena de morte é claramente construída pela trama ficcional: condenado à morte, Motta Coqueiro será absolvido pelo leitor depois que este descobre o "verdadeiro autor do crime". Todavia, a leitura panorâmica não é um bom itinerário se o leitor deseja apreender a massa sensível em que o romance de Patrocínio se assenta. No sentido empregado aqui, o sensível diz respeito tanto a uma percepção dos afetos traduzida na malha textual quanto à produção de afetos. O sensível se aproxima, como mostraremos, de uma sintomatologia. ${ }^{6}$

5 PATROCÍNIO. Motta Coqueiro ou A pena de morte, p. 25-26.

6 A sintomatologia na condição do oprimido pelo racismo é articulada, exemplarmente, no trabalho de Shirlei Campos Victorino. Ao discutir a poesia negra-brasileira, a autora comenta que: "A literatura como sintoma, ou como letra que ancora o sujeito na vida [...] remete à pulsão, projeta uma relação simbiótica entre o que se é, o que se espera, e o que se espelha. As lutas internas raciais, sexuais e de classe, bem como as diferentes histórias culturais que definem quem somos nós como seres sociais, impedem nossa união em torno de objetivos comuns" (VICTORINO. Escrita do sintoma, escrita da letra: notas sobre a poesia negra-brasileira em voz feminina, p. 1). 
Ainda na abertura do romance, são notáveis os contracampos ${ }^{7}$ da cena do enforcamento. O narrador desvia o olhar do leitor dessa cena para cenas paralelas, descritas para assegurar sua tese:

Na direção indicada pelo interlocutor estava levantada a máquina sombria da justiça social.

A sua fealdade comovente, brutal encarnação dos sentimentos da população, pavoneava-se, entretanto, com o epíteto honroso de instrumento da desafronta pública.

Todos fitavam-na com simpatia, com estremecimento mesmo, e cada um buscava tomar posição apropriada a tê-la de frente.

Talvez pela imaginação exaltada do povo passassem as imagens das vítimas imoladas à sanha facinorosa dos seus matadores.

Diante da horrorosa construção, a memória popular avivava recordações de outros tempos, ouvidas em serões de família aos pais já finados. ${ }^{8}$

É perceptível que a cena é montada por meio de uma série de adjetivos que retoricamente induzem a uma sensação a ser experimentada: esse recurso é explorado, nesse trecho, pelo uso do adjetivo, como em "máquina sombria da justiça social", "fealdade comovente" e, muito dramaticamente, a "sanha facinorosa dos seus matadores". Diferentemente do uso mais austero da linguagem jornalística (ainda que a imprensa no século XIX flertasse com o ornamental), a linguagem no romance movimenta, aliando tese e retórica, o sensível que a letra pode produzir.

Conforme assinalava Silviano Santiago no ensaio sobre Motta Coqueiro, esse desvio do ficcional se configura na defesa de tese, sobretudo quando o discurso da narrativa de Patrocínio parece ler ambientes, objetos, gestos, como sintomas do engano da condenação. Por esse viés, o romance de tese se confirma, e a narrativa é vítima de um enquadramento redutor. Contudo, Patrocínio utiliza esse recurso da sintomatologia para outro fim ainda mais desafiador: a partir desses sintomas, o narrador vai tecendo uma malha do sensível que envolve a sociedade brasileira do século XIX, e que a narrativa de Motta Coqueiro e o espaço de Macaé exemplificam.

Exemplarmente, na cena de enforcamento, o narrador desvia o olhar do leitor para o carrasco:

7 Faço uso do termo ligado ao cinema, já que ele pode traduzir a sensação de o leitor perceber, a partir de um esforço de atenção, cenas narradas ao fundo da cena principal. 8 PATROCÍNIO. Motta Coqueiro ou A pena de morte, p. 29. 
Havia, porém, um homem em quem a solenidade singela do ofício divino não produzia a menor impressão. Era o carrasco, o monstro negro, que brincava distraidamente com o seu barrete, revolvendo-o entre as mãos.

Estátua informe da escravidão, cujas falhas foram cheias com o asfalto do calabouço, argamassado com o sangue que os açoutes lhe tiraram do corpo, o desgraçado folgava talvez na sua brutalidade de fera.

Os brancos fizeram dele uma vítima; proibiram-lhe que afinasse os sentimentos pela compreensão exata da família, da religião e da pátria; devia ser-lhe grato poder vingar-se de um dos seus opressores. ${ }^{9}$

É a partir dessa descrição contundente que começa a se desenhar, na narrativa, o clima complexo da sociedade escravocrata: a pena de morte, a condenação do senhor de escravizados, representado sempre como homem íntegro na ficção, e a vítima-algoz, representada pelo carrasco, são lados de uma condenação que também atinge escravizados, agregados, mestiços e pobres. Todos condenados ao ódio. O caso Motta Coqueiro parece revisitar, embora em diferença, a tese do romance Vitimas-algozes, de Joaquim Manoel de Macedo, publicado em 1869. Neste, o abolicionismo visa livrar os senhores da vingança dos escravizados, do inimigo à espreita. Na obra de Patrocínio, a defesa de Motta Coqueiro diante da aceitação massiva de sua culpa é extensível à crítica à escravidão que fomenta os crimes de ódio: ódio contra Motta Coqueiro, mas também contra a família de Francisco Benedito e suas filhas, cobiçadas pelo desejo misógino, e, principalmente, contra escravizados, conforme depoimento da escrava Balbina, e contra os mestiços, como o personagem Manuel José, sobre quem recai uma série de termos depreciativos. O que se evidencia é o ódio em toda a sua força de alastramento - o fogo na casa da família assassinada é a um só tempo índice e símbolo desse ódio.

É relevante que Patrocínio evite o maniqueísmo redutor: numa sociedade escravocrata, o ódio é o calor que choca o ovo da serpente. As quase 40 vezes em que a palavra ódio aparece no romance talvez sejam indícios de como a história de Motta Coqueiro pode, nas mãos

PATROCÍNIO. Motta Coqueiro ou A pena de morte, p. 36. 
do romancista, servir para mostrar as camadas de ódio dessa sociedade. Estilisticamente, a expressão do ódio para Patrocínio é a zoomorfização:

A fria premeditação do feitor espojava-se então na hediondez dos instintos sanguinários, como o porco farto no lamaçal do chiqueiro. E como no focinho alongado e negro do animal ficam a branquear as duas longas presas curvas, no rosto do assassino intencional ficavam sempre à mostra o despeito e o ódio. ${ }^{10}$

A zoomorfização ${ }^{11}$ é um dos recursos expressivos e ideológicos disponíveis na sociedade oitocentista brasileira. Posteriormente, esse recurso foi largamente empregado pelo Naturalismo brasileiro, que se forja no ambiente de propagação de ideias cientificistas e projetos de interpretação do humano. A zoomorfização constitui um modo de hierarquizar certas condutas humanas - consideradas inatas ou não marcadas pelo primarismo. Por isso, não é raro que a zoomorfização seja empregada na descrição dos afrodescendentes - escravizados ou não - ou dos representantes das classes sociais ditas baixas.

Assim, Patrocínio segue em Motta Coqueiro as tendências expressivas de sua época; contudo, sua singularidade se mostra no emprego dessas tendências para figurar a malha de ódio que recobre a sociedade brasileira do século XIX, como confirmam inúmeras passagens da obra:

A odiosidade de que vivia cercado em Macabu, as provocações de que era alvo para que desorientassem-no dos caminhos da prudência e perdessem-no numa precipitação; as calúnias que arrebentavam do anônimo, à semelhança de uma nuvem de mosquitos de um pântano, assediavam-no entre zunidos importunos e mordidelas incômodas; as ciladas que a todo o momento enredavam-lhe os passos; o seu viver de isolamento que, averbado de misantropia, abria largo e atraente campo às intrigas as mais abstrusas, tudo isso borbulhou da memória do fazendeiro

${ }^{10}$ PATROCÍNIO. Motta Coqueiro ou A pena de morte, p. 72.

11 Embora os recursos ocorram em contexto diverso, aproximamos a zoomorfização percebida em Patrocínio ao modo como Aluísio Azevedo emprega a caracterização zoomórfica em $O$ cortiço. É assim que Affonso Romano de Sant'Anna percebe o recurso no escritor maranhense: "Os elementos marcam-se pela sua impessoalidade, dissolvidas na comunidade instintiva e animal” (SANT'ANNA. Análise estrutural de romances brasileiros, p. 123). 
e, escoando-se pelos raciocínios exaltados, alagou-lhe o coração de uma inundação de fel. ${ }^{12}$

Eu sou filho de caboclo; do goitacás que odeia sem barulho, que sofre sem queixar-se, que morre sem gemer. Meu pai acostumoume em criança a passar o dia à popa de uma canoa à espera que o piau farto se levantasse do fundo do rio, e viesse colocar-se ao alcance das nossas flechas. Estas atravessavam as águas sem ruído e a morte do peixe, que durante longas horas espiávamos, se anunciava apenas pela cor do sangue que vinha à flor do rio. Espero, esperarei para matar assim. Do que me serviria matar, para vingar-me, se ao cabo iria parar a uma prisão, onde a minha existência seria ainda mais cruel.

Eu não peço a você que me ajude, peço apenas que não me faça perder tantos anos dedicados à minha vingança. Este ódio é a minha vida, tirem-no, e eu morrerei. Para satisfazê-lo, hei de fazer cair quantos encontre em meu caminho. E qual é a causa que o move? No dia em que nos encontramos, vosmecê disse-me somente: "Não é assim que um homem se desforra; segue-me." Acompanhei-o; nunca perguntou-me sequer por que razão eu ia perpetrar um crime, e nunca também me disse o seu nome, nem perguntou pelo meu. Pensa talvez que eu sou levado por uma questão sem valor, por uma criançada, e zomba de mim. ${ }^{13}$

Todos queriam ver o réu principal, decididos a apascentar as manadas de apóstrofes de promotoria e ódio insaciável, que baliam-lhes esfaimadas, conchegando-se agora e para logo estramalhando-se do aprisco moral, construído por uma certa boa fé de convenção, que levava os homens, ainda os mais sisudos, a trapilharem maldições nos esterquilínios formados pela intriga em roda dos caracteres limpos. ${ }^{14}$

Acredito que a sequência acima seja suficiente para o leitor de Patrocínio perceber que a retórica ficcional do libelo contra a pena de morte não poderia se fazer sem essa radiografia do sensível que a narrativa apresenta, mapeando as relações vincadas no ódio. Segundo o filósofo Gabriel Liiceanu (2014), as últimas décadas do século XIX

12 PATROCÍNIO. Motta Coqueiro ou A pena de morte, p. 124.

13 PATROCÍNIO. Motta Coqueiro ou A pena de morte, p. 194.

${ }^{14}$ PATROCÍNIO. Motta Coqueiro ou A pena de morte, p. 234. 
testemunharam a metamorfose da carga psíquica e simbólica do ódio em organização; "o que descobriria, juntamente com Marx, o final do século XIX é que o ódio pode ser organizado. Dito de outro modo, ele pode ser induzido, argumentado, explicado, teoretizado, previsto como um escopo, com um programa e posto de modo sistemático a trabalhar". ${ }^{15}$ Sendo assim, que justiça justa seria possível no império do ódio, numa sociedade estruturalmente escravocrata?, podemos nos perguntar a partir da possibilidade de leitura que o texto de Patrocínio nos oferece. Figurando uma espécie de homo sacer, ${ }^{16}$ o Motta Coqueiro de Patrocínio repete os passos rumo ao calvário. A cena de abertura é construída como uma cena crística, de lavagem de mãos, o que leva o narrador a vislumbrar:

Seguia-se imediatamente ao painel um sacerdote tendo nas mãos uma grande cruz, na qual abriam-se os braços e confrangia-se o corpo lívido de um Cristo ensanguentado, cuja face voltava-se para o lado do padecente.

A poucos passos da cruz e lateralmente a ela, vinha o porteiro tendo nas mãos um papel, em que estava exarada a sentença lavrada pelo tribunal contra o réu. ${ }^{17}$

\section{Macaé, Alcolu, Ferguson}

Evidentemente, a defesa do narrador assume um discurso moral com o objetivo de esclarecer o leitor: a versão do romance existe para desvendar os caminhos tortuosos de supostos equívocos no processo judicial, especialmente corrompido, porque a corrupção é inerente a uma sociedade assinalada pelo ódio e pela vingança. A opinião e a disputa política também condenam. A criação de Horácio, confessor que aparece no final do romance, confunde os juristas da época, o que

\footnotetext{
${ }^{15}$ LIICEANU. Do ódio, p. 48.

${ }^{16}$ O conceito de homo sacer foi posto contemporaneamente em circulação pela série de escritos do filósofo italiano Giorgio Agamben, especialmente na obra Homo sacer: o poder soberano e a vida nua, v. I (2002). No homo sacer, os modelos biopolítico e jurídico-institucional do poder têm sua junção: é nessa vida exposta, "nua", que a soberania do Estado exerce uma necropolítica, como desenvolve Achille Mbembe (2018), delineando corpos matáveis.

${ }_{17}$ PATROCÍNIO. Motta Coqueiro ou A pena de morte, p. 32.
} 
denuncia a fragilidade do processo. Pensemos no debate, ${ }^{18}$ publicado com o nome de "A angústia de julgar", reunindo Michel Foucault, Jean Laplanche e o advogado criminalista Robert Badinter, em que se discutiu a pena de morte a partir do caso de P. Henry, que sequestrou um menino e o enforcou. $\mathrm{O}$ apelo do criminoso pela pena mais severa, mas não a guilhotina, reacenderia o debate sobre a pena de morte, finalmente abolida em 1981 na França. Mas o que o apelo de Henry levantou foi a discussão sobre os limites de fidedignidade de um processo judiciário, o que torna a pena capital um problema ético. Para Foucault, a pena capital revela a lógica obscura da sociedade punitiva que encarna o crime no criminoso, tornando-o um objeto a ser eliminado, justificando sua morte. É manifesto o interesse de Foucault pela dita "sociedade punitiva", que o filósofo debate no curso de mesmo nome realizado em 1972-1973. ${ }^{19}$ Nesse curso, Foucault argumenta que a pena de morte, no sistema de reclusão, significa a reclusão definitiva que substitui os castigos corporais.

Percebe-se que, em Motta Coqueiro, a defesa de tese e a denúncia de uma sociedade escravocrata estão imbricadas: ser contra a pena de morte e ser contra a escravidão não são posturas de lutas separadas, uma vez que as duas posições são tentativas de compreender o escuso que contamina todas as esferas onde o poder é exercido, especialmente onde o biopoder ${ }^{20}$ é exercido: escravização, submissão do corpo, aprisionamento, encarceramento e pena de morte.

Essa junção entre biopoder e racialização é muito bem compreendida por Achille Mbembe (2018). De acordo com o filósofo, a soberania de um povo, que subjaz à constituição de uma sociedade nos moldes do nacionalismo, é também organizada a partir de uma necropolítica: o direito e o dever de matar. E a racialização é um de seus fundamentos:

${ }^{18}$ FOUCAULT. Ditos e escritos: Segurança, penalidade e prisão, p. 73-90.

${ }^{19}$ FOUCAULT. A sociedade punitiva, 2015.

${ }^{20}$ O conceito de biopoder, conforme elaborado por Foucault, a partir de 1974, tem como alcance o exercício de práticas de controle e vigilância sobre os corpos nas instituições (escola, prisão, hospital, etc.) e a regulação das populações (mecanismos de controle de fluxos, como mortalidade, crescimento demográfico, etc.). Os filósofos Giorgio Agamben e, sobretudo, Achille Mbembe, dentre outros pensadores, nos interessam aqui como rearticuladores do conceito de biopoder a fim de perceber tal exercício do poder na decisão sobre a vida e a morte de certos corpos dentro de determinadas sociedades. 
Com efeito, em termos foucaultianos, racismo é acima de tudo uma tecnologia destinada a permitir o exercício do biopoder, "este velho direito soberano de matar". Na economia do biopoder, a função do racismo é regular a distribuição da morte e tornar possíveis as funções assassinas do Estado. ${ }^{21}$

Se iniciei este artigo pondo em relação os acontecimentos de Ferguson, Alcolu e Macaé, juntamente com o folhetim de José do Patrocínio, foi porque essa relação constitui uma pequena constelação que deixa entrever como a expressão da negritude no livro de Patrocínio poderia ser lida de um ângulo específico: a partir da complexa organização social que precipita os crimes de ódio e o exercício do biopoder. Faces desse problema complexo, a pena de morte e a execução de afrodescendentes pobres irmanam-se em sociedades estruturadas pelo ódio, sobretudo as que partilham, na sua gênese, do sistema escravocrata.

Evidentemente, a punição a escravizados negros e aquela destinada a brancos pobres, porém livres, não são análogas, pois a diferenciação tanto de privilégios quanto de punições é constituinte de um sistema desigual. Todavia, como essa diferenciação não é uma marca na ficção de Patrocínio abordada aqui, a leitura da obra nos leva a perceber que Patrocínio, ao não ter marcado, de forma mais ostensiva, um ponto de vista da negritude, mantendo-se na tese da injustiça a um branco privilegiado, provoca a abertura para uma reflexão mais distanciada, a que pode mostrar como uma sociedade escravocrata corrói todos os caminhos em que a justiça poderia ser feita.

Ferguson, Alcolu, Macaé nos lembram que a violência, o ódio e a escravização são pensáveis globalmente, como defende a filósofa Angela Davis (2018). Se o biopoder e o exercício da violência policial ou jurídica são exercidos pelo Estado em defesa de uma soberania, o pensamento e a consequentemente contestação a esses atos, segundo Davis, devem ser sobrepostos globalmente, para que apreendam os mecanismos excludentes em amplo contexto:

Por que eu afirmo que Ferguson nos lembra da importância de um contexto global? O que observamos na reação da polícia à resistência que irrompeu espontaneamente como consequência do

${ }^{21}$ MBEMBE. Necropolitica, p. 18. 
homicídio de Michael Brown foi uma resposta armada que revelou até que ponto as forças policiais locais têm sido equipadas com armamentos militares. ${ }^{22}$

Ferguson, Alcolu e Macaé nos lembram disso. Motta Coqueiro ou A pena de morte, por sua vez, nos lembra que a expressão de negritude na literatura de Patrocínio é também contestação do direito e do dever de matar que atinge a todos. Assim, o folhetim se alinha a uma genealogia possível, dentro da literatura afro-brasileira, de obras de denúncia social, contra o racismo, e de expressão da negritude. Na Macaé de Patrocínio, o senhor de escravizados pode ser morto não somente pelo ódio que estes sentem por ele, mas por uma estrutura de ódio que produz condenados à injustiça na mesma medida em que produz condenados à miséria e à vingança.

\section{Referências}

AGAMBEN, Giorgio. Homo sacer: o poder soberano e a vida nua. Belo Horizonte: Editora UFMG, 2002. v. I.

DAVIS, Angela. A liberdade é uma luta constante. São Paulo: Boitempo, 2018.

FOUCAULT, Michel. A sociedade punitiva. São Paulo: Martins Fontes, 2015.

FOUCAULT, Michel. Ditos e escritos: segurança, penalidade e prisão. Rio de Janeiro: Forense Universitária, 2012. v. 3.

MAGALHÃES JR., Raimundo. A vida turbulenta de José do Patrocínio. Rio de Janeiro: Sabiá, 1969.

MBEMBE, Achille. Necropolítica. São Paulo: n-1 Edições, 2018.

PATROCÍNIO, José do. Motta Coqueiro ou A pena de morte. Rio de Janeiro: Instituto Estadual do Livro, 1977.

SANT'ANNA, Affonso Romano de. Análise estrutural de romances brasileiros. São Paulo: Editora Unesp, 2012.

${ }^{22}$ DAVIS. A liberdade é uma luta constante, p. 29. 
SANTIAGO, Silviano. Desvios da ficção. In: PATROCÍNIO, José do. Motta Coqueiro ou A pena de morte. Rio de Janeiro: Instituto Estadual do Livro, 1977. p. 11-21.

SOUZA, Marcos Teixeira. José do Patrocínio: uma trajetória em meio a memórias. Grau Zero - Revista de Crítica Cultural, Alagoinhas, BA, v. 3, n. 1, 2015. Disponível em: <http://www.revistas.uneb.br/index.php/ grauzero/article/view/3283>. Acesso em: 2 jul. 2018.

VICTORINO, Shirlei Campos. Escrita do sintoma, escrita da letra: notas sobre a poesia negra-brasileira em voz feminina. Revista Cátedra Digital, Rio de Janeiro, v. 2, 2016. Disponível em: <http://revista.catedra.puc-rio. br/index.php/2016/12/07/escrita-do-sintoma-escrita-da-letra-notas-sobrepoesia-negra-brasileira-em-voz-feminina/>. Acesso em: 2 jul. 2018.

Recebido em: 11 de julho de 2018. Aprovado em: 13 de setembro de 2018. 